\title{
Tillage impacts on the fractions and compositions of soil organic carbon
}

\author{
Hong Zhao ${ }^{\text {a }}$, Yizhong Lv ${ }^{\mathrm{b}, *}$, Xiaoke Wang ${ }^{\mathrm{a}}$, Hailin Zhang ${ }^{\mathrm{c}}$, Xueming Yang ${ }^{\mathrm{d}}$ \\ a State Key Laboratory of Urban and Regional Ecology, Research Center for Eco-Environmental Sciences, Chinese Academy of Sciences, Beijing 100085, China \\ b College of Resources and Environment, China Agricultural University, Beijing 100193, China \\ c College of Agriculture and Biotechnology, China Agricultural University, Beijing 100193, China \\ d Greenhouse and Processing Crops Research Centre, Agriculture and Agri-Food Canada 2585 County Road 20, Harrow, Ontario, Canada NOR 1G0
}

\section{A R T I C L E I N F O}

\section{Article history:}

Received 20 January 2011

Received in revised form 31 May 2012

Accepted 1 June 2012

Available online 18 August 2012

\section{Keywords:}

Black soil

Carbon associated with aggregates

CPMAS ${ }^{13} \mathrm{C}$ NMR

Functional group

\begin{abstract}
A B S T R A C T
This study aimed to reveal the impacts of tillage systems on the fractions (active, slow, and passive carbon) and chemical compositions of soil organic carbon (SOC). A long-term (26 years) tillage experiment in northeast China examined no-tillage (NT), plowing tillage (PT) and deep loosing (DL). The soil samples (from a depth of $0-20 \mathrm{~cm})$ were wet-sieved into five aggregate classes $(1000-2000 \mu \mathrm{m}, 500-1000 \mu \mathrm{m}, 250-$ $500 \mu \mathrm{m}, 50-250 \mu \mathrm{m}$, and $<50 \mu \mathrm{m}$ ). The active carbon (C) and passive $C$ were detected in the $500-1000 \mu \mathrm{m}$, 250-500 $\mu \mathrm{m}$, and 50-250 $\mathrm{m}$ aggregates, and the chemical compositions of SOC in micro-aggregates $(<250 \mu \mathrm{m})$ and macro-aggregates $(>250 \mu \mathrm{m})$ were assessed by CPMAS ${ }^{13} \mathrm{C}$ NMR.

Macro-aggregates contained more SOC concentration than micro-aggregates. However, PT resulted in a greater SOC concentration in 50-500 $\mu \mathrm{m}$ aggregates. NT and DL increased the active $C$ and decreased the slow $C$ in 500-1000 $\mu$ m aggregates, whereas PT showed the inverse. The ${ }^{13} \mathrm{C}$ NMR spectrum demonstrated that NT increased alkyl-C content, PT obtained a higher carbonyl-C concentration, and DL gained a greater O-alkyl-C concentration. Moreover, evaluating the impacts of tillage systems on the complexity revealed that the most complicated structure was presented in NT, the least in PT, whereas DL had an intermediate effect. Active C contains C2-C6 carbohydrate and anomeric C (C1) polysaccharides, slow C consists of aldehyde- $C$, ketonic- $C$ and quinone- $C$, and the passive $C$ is enriched in aromatic- $C$. In conclusion, long-term tillage systems significantly affected the fractions and compositions of SOC, with NT stabilizing the SOC.
\end{abstract}

(C) 2012 Elsevier B.V. All rights reserved.

\section{Introduction}

The black soils (mollisols) of China were once the most fertile soils in the world, but its fertility has been degraded as indicated by the decrease of soil organic carbon (SOC). The annual loss of SOC stocks could reach $2.05 \mathrm{Mg} \mathrm{ha}^{-1}$ in the northeast of China (Qiu et al., 2004), and approximately 30\% of the SOC in the cropland soils of Heilongjiang Province was lost during the past 30 years (Meng and Liu, 2008). The $C$ loss of black soils is severe; in fact, the processes of SOC sequestration and destabilization were both controlled in the molecular level. The molecular structure and chemical composition of SOC control its content and steady state. A number of studies analyzed the chemical composition of SOC to characterize its stability (Ding et al., 2002; Mahieu et al., 1999; Pérez et al., 2004). The chemical composition of SOC includes alkyl-C, O-alkyl-C, aromatic-C and carbonyl-C. Generally, the labile composition of SOC contributes to

\footnotetext{
* Corresponding author. Tel.: +8610 62733217; fax: +861062733596. E-mail address: lyz@cau.edu.cn (Y. Lv).
}

the release of soil carbon and the stable composition of SOC favors the conservation of C. Although Preston et al. (1994) considered that the composition of SOC had little variance under different crop management systems, recently many researchers have expressed a contrary view (e.g., Chen and Chiu, 2003; Helfrich et al., 2006). Some reports found obvious changes in the composition of soil organic matter after shifting from no tillage to plowing tillage (e.g. Dieckow et al., 2009), furthermore, the study of Solomon et al. (2007) highlighted the decline of O-alkyl $\mathrm{C}$, acetal-C and aliphatic $\mathrm{C}$ after a long-term of anthropogenic perturbations for tropical forest and sub-tropical grassland ecosystems.

Parton et al. (1987) divided SOC into three fractions, including active SOC [the mean residence time (MRT) is about $1-5$ years cycle], slow SOC (MRT is about 20-40 years), and passive SOC (MRT is about 200-1500 years). A number of recent researches have focused primarily on the SOC pools (Franzluebbers and Arshad, 1997; Yang and Kay, 2001; Sotomayor-Ramírez et al., 2006; Tan et al., 2007); however, there is still a lack of information about the chemical compositions of SOC in soils under various tillage management practices. Accordingly, the objective of this paper is to assess the effects of 
tillage systems on the sizes and chemical compositions of SOC pools in water-stable soil aggregates of black soil that have undergone 26 years of no tillage (NT), plowing tillage (PT), and deep loosing (DL) management in northeast China.

\section{Materials and methods}

\subsection{Study site}

This study was conducted at the long-term tillage experiment located at Gongzhuling, Jilin Province, northeast China $\left(43^{\circ} 31^{\prime} \mathrm{N}\right.$, $124^{\circ} 48^{\prime}$ E). The experiment began in 1983 with continually cropped mono-culture maize [Zea mays L.]; mean annual temperature is $5.6^{\circ} \mathrm{C}$, with mean annual precipitation of $562 \mathrm{~mm}$. The soil of the experimental site was classified as a typical clay-silt black soil (typic hapludoll, USDA soil taxonomy), with quaternary loess-like sediment as parent material, $29.61 \mathrm{~g} \cdot \mathrm{kg}^{-1}$ soil organic matter, $1.60 \mathrm{~g} \cdot \mathrm{kg}^{-1}$ total nitrogen, $0.52 \mathrm{~g} \cdot \mathrm{kg}^{-1}$ total phosphorus, $19.40 \mathrm{~g} \cdot \mathrm{kg}^{-1}$ total potassium, and a pH of 6.40 in the depth of $0-20 \mathrm{~cm}$.

\subsection{Experimental design and soil sampling}

The experiment included three tillage systems: (1) plowing tillage (PT), adopt to moldboard plowing after the autumn harvest (tillage depth about $20 \mathrm{~cm}$ ), with $0.70 \mathrm{Mg} \mathrm{ha}^{-1}$ maize straw incorporation, (2) no-tillage (NT), no soil disturbance except planting, with $2.78 \mathrm{Mg} \mathrm{ha}^{-1}$ maize straw incorporation, and (3) deep loosing (DL), chopped and disk incorporated into $8-10 \mathrm{~cm}$, followed by a deep loosing operation to $30-40 \mathrm{~cm}$ using a deep cultivator, with $2.78 \mathrm{Mg} \mathrm{ha}^{-1}$ maize straw incorporation. From the inception of the experiment, maize straw was introduced into the soil annually to prevent water and soil losses. This was accomplished by a vertical method, but was not mixed with the soil. The experiment was a randomized block design with three replicates for each tillage treatment. Each plot was $8 \mathrm{~m}$ wide by $150 \mathrm{~m}$ long.

Before maize was planted in April 2009, soils were sampled at a depth of $0-20 \mathrm{~cm}$ in the research site. Each sample was a composite of three soil core per replicate for each tillagement; samples were randomly collected by the use of a flat spade. Soil samples were gently broken apart and passed through an $8-\mathrm{mm}$ sieve, and then airdried before the physical and chemical analysis.

\subsection{Laboratory analyses and calculations}

\subsubsection{Aggregate-size distribution}

The fraction of aggregates was measured using a wet sieving method (Kemper, 1986). Air-dried soil samples of $50 \mathrm{~g}$ were placed at the top of a stack of sieves $(2000,1000,500,250$, and $50 \mu \mathrm{m})$. The screen was lowered to the water surface to allow the dry soils to become moist via capillary action, and then soils were sieved for $10 \mathrm{~min}$ with a stroke length of $10 \mathrm{~cm}$ and a frequency of 35 strokes per minute. Soils that remained in each sieve were transferred to a container, dried $\left(60^{\circ} \mathrm{C}\right)$, and weighed.

\subsubsection{Soil organic carbon measurement}

Soil samples of $350 \mathrm{mg}(<250 \mu \mathrm{m})$ were analyzed using wet combustion to measure total soil organic carbon (SOC) concentration (Bao, 2000). Active SOC was determined using the $\mathrm{KMnO}_{4}$ oxidation method (Yu et al., 2005), in which soil samples containing about $15 \mathrm{mg} \mathrm{SOC}$ were put into $333 \mathrm{mmol} \cdot \mathrm{L}^{-1} \mathrm{KMnO}_{4}$ solution $(25 \mathrm{ml})$, oscillated for $1 \mathrm{~h}$ to oxidize active SOC, and the amount of active SOC was quantified by the amount of $\mathrm{KMnO}_{4}$ consumption. Passive SOC was measured by using acid hydrolysis (Leavitt et al., 1996), taking more than $5 \mathrm{~g}$ of soils into a test tube containing $6 \mathrm{~N} \mathrm{HCl}$, boiled the soils for $16 \mathrm{~h}$ and then washed the samples to $\mathrm{pH}=7.0$ with distilled water, dried the samples in an oven of $60^{\circ} \mathrm{C}$, and the carbon of these samples was quantified as passive SOC by using wet combustion. The slow SOC was defined as the difference between the SOC and the sum of active and passive SOC. Small amounts of samples were left in $1000-2000 \mu \mathrm{m}$ and $(<50) \mu \mathrm{m}$ after wet-sieved, therefore, it only determined active and passive $\mathrm{C}$ concentration in the aggregates of 50-1000 $\mu \mathrm{m}$.

\subsubsection{NMR spectra analysis}

About $6 \mathrm{~g}$ subsamples of each sample (bulk soil and aggregates) were placed into $100 \mathrm{ml}$ polyethylene bottle and $50 \mathrm{ml}$ 10\% HF (w/w) was added. After sealing the bottle, the suspension of HF and bulk soil was shaken for $2 \mathrm{~h}$ in oscillator. And then the sample was centrifuged for $10 \mathrm{~min}$ at $5000 \mathrm{rpm}$ and the supernatant was discarded. This process was replicated four times. The residue was washed four times with $40 \mathrm{ml}$ of deionized water, and the remaining samples freeze-dried (Goncalves et al., 2003). All of the above processes are used for the pretreatment of soil samples.

Solid-state ${ }^{13} \mathrm{C}$ NMR spectra were acquired at the ${ }^{13} \mathrm{C}$ resonance frequency of $100.46 \mathrm{MHz}$ on a Bruker DSX spectrometer (BRUKER DSX 750 spectrometer, Karlsruhe, Germany), with more than $0.5 \mathrm{~g}$ samples in 7-mm diameter sample tubes. The cross polarization magic angle spinning (CP MAS) technique was applied with a contact time of $3 \mathrm{~ms}$, spinning speed of $5000 \mathrm{~Hz}$, and a pulse delay of $1 \mathrm{~s}$, 20,000 scans were collected from the soil samples.

The spectra of CPMAS ${ }^{13} \mathrm{C}$ NMR were divided into four main chemical shift regions: alkyl-C ( -10 to $45 \mathrm{ppm}$ ), O-alkyl C (45 to $110 \mathrm{ppm}$ ), aromatic-C (110 to $160 \mathrm{ppm}$ ), and carbonyl-C (160 to $220 \mathrm{ppm})$. Oalkyl C was further separated into methoxyl-C (50 to $60 \mathrm{ppm}$ ), C2-C6 carbohydrates (60 to $95 \mathrm{ppm}$ ) and polysaccharides of anomeric-C (C1) (95 to $110 \mathrm{ppm}$ ); aromatic-C was divided into aryl-C (110 to $140 \mathrm{ppm}$ ) and phenolic-C (140 to $160 \mathrm{ppm}$ ); and carbonyl-C was detailed allocated in carboxylic acid-C (165 to $175 \mathrm{ppm})$ and aldehyde- $C$, ketonic- $C$ and quinone- $C$ (185 to 220 ppm). The chemical shift regions were expressed as a percentage of the area of the total spectrum. The relative contents of the different chemical structures were obtained from the area under the spectra of ${ }^{13} \mathrm{C}$ NMR.

\subsubsection{Data analysis}

The various (active, passive and slow) SOC concentrations in aggregate fractions were subjected to analysis of variance (ANOVA) using the GLM of SPSS 16.0 software. Multiple comparisons of means were conducted using LSD when ANOVA was significant at $\mathrm{P}<0.05$. Correlations between carbon fractions were expressed using the Pearson index with significant level of $\mathrm{P}<0.05$ unless otherwise stated.

\section{Results}

\subsection{Effects of tillage practices on soil organic carbon}

\subsubsection{SOC content in soil aggregates}

SOC concentration $(0-20 \mathrm{~cm})$ showed no significant variation in bulked soil among three tillage systems; however, obvious differences of SOC concentration were detected in different sizes of aggregates (Fig. 1). The main difference in SOC concentration occurred at the aggregates of $50-250 \mu \mathrm{m}$, and $(<50) \mu \mathrm{m}$ SOC levels of $50-250 \mu \mathrm{m}$ were on an average of $15.18 \%$ and $16.03 \%$ higher in PT vs. NT and DL, and SOC levels in aggregate of $(<50) \mu \mathrm{m}$ were on a mean of $36.88 \%$ higher for PT and DL than NT. In addition, macro-aggregates $(>250 \mu \mathrm{m})$ were associated with a greater SOC concentration than micro-aggregates $(<250 \mu \mathrm{m})$, but at PT, SOC concentration existed no significant variance between 50-250 $\mu \mathrm{m}$ and macro-aggregates.

\subsubsection{Impacts of tillage on the SOC in aggregates}

Different tillage systems also influenced the $C$ fractions in soil aggregates (Fig. 2). PT was 53.03\% and $72.72 \%$ lower than NT and DL in 


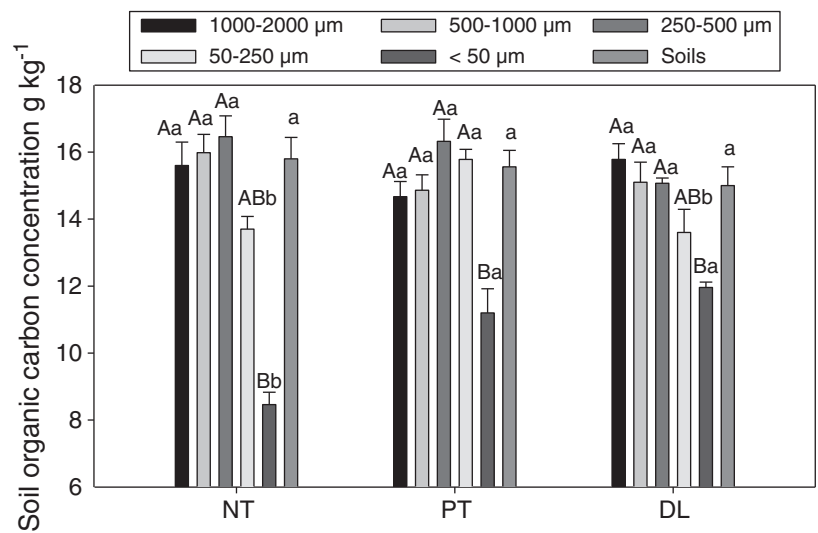

Fig. 1. Effect of NT, PT and DL on organic carbon concentration in bulk soils and wet-sieved aggregates.

Note: Same capital letter X indicates no significant difference of SOC concentration at $\mathrm{P}<0.05$ level in the different aggregates-size, same lowercase $\mathrm{x}$ represents no significant difference of SOC concentration at $\mathrm{P}<0.05$ level under different tillage systems.

active C concentration of 500-1000 $\mu \mathrm{m}$ aggregate, and active SOC in PT soils increased with the decrease of aggregate size. In contrast, PT vs. NT and DL would increase slow SOC by $18.77 \%$ and $24.86 \%$ in 500-1000 $\mu \mathrm{m}$ aggregate, respectively. Furthermore, at PT, the slow SOC of $500-1000 \mu \mathrm{m}$ aggregate was higher $36.06 \%$ compared with $50-500 \mu \mathrm{m}$ aggregate. No significant difference was found in the passive SOC concentration associated with different tillage systems and different sizes of aggregates.

\subsection{Composition of soil organic carbon}

\subsubsection{Aggregate ${ }^{13} \mathrm{C}$ NMR spectroscopy}

Solid-state ${ }^{13} \mathrm{C}$ NMR spectra of SOC in different soil aggregates extracted from three tillage systems are presented in Figs. 3 and 4, which appear as the similar chemical-shifts. The resonance peak of alkyl-C shows to $23 \mathrm{ppm}$ and $30 \mathrm{ppm}$; the signal intensity of $\mathrm{O}-$ alkyl-C appears at 55 ppm, 62 ppm, 73 ppm and 103 ppm; the peak of aromatic-C occurs at $124 \mathrm{ppm}$; the signal of $150 \mathrm{ppm}$ is very weak; the resonance peak of carbonyl-C appears at $173 \mathrm{ppm}$.

\subsubsection{Compositions of SOC}

The highest content was found in O-alkyl-C among the different functional groups, on average, O-alkyl-C accounted for $39.84 \%$, $41.68 \%$ and $43.08 \%$ of the total C for the NT, PT and DL soils, respectively (Tables 1 and 2 ). Aromatic-C content responded similarly to three tillage systems in macro-aggregates, whereas greater aromaticC content was detected in micro-aggregates for NT and DL than PT. In addition, carbonyl-C content is a declining trend in the order of $\mathrm{PT}>\mathrm{NT}>\mathrm{DL}$ in micro-aggregates and macro-aggregates.

The $\mathrm{O}$-alkyl-C, aromatic- $\mathrm{C}$ and carbonyl- $\mathrm{C}$ regions were further separated in different aggregates (Tables 1 and 2). Tillage systems have little impact on the methoxyl-C content for the soils, but the methoxyl-C content was $7.8 \%$ to $11.5 \%$ higher in the microaggregates compared with macro-aggregates. The C2-C6 carbohydrate and anomeric-C (C1) in different tillage systems are showed in the order of DL $>$ PT $>$ NT, and the NMR chemical shift of C2-C6 carbohydrate and anomeric- $\mathrm{C}(\mathrm{C} 1)$ is similar to O-alkyl-C. The trends of aryl- $\mathrm{C}$ and aromatic- $\mathrm{C}$ are consistent, but phenolic- $\mathrm{C}$ and aromatic- $\mathrm{C}$ indicate an opposite trend, in micro-aggregates, additionally, aryl-C content in micro-aggregates increased by $8.8 \%-17.8 \%$ under NT and DL vs. PT, respectively. The carbonyl-C content in different aggregates has the similar value, but the aldehyde- $C$, ketonic- $C$ and quinone- $C$ content was lower in micro-aggregates vs. macro-aggregates.

The alkyl-C/O-alkyl-C ratio can be taken as an indicator to assess the degree of decomposition of SOC. Therefore, it can be considered
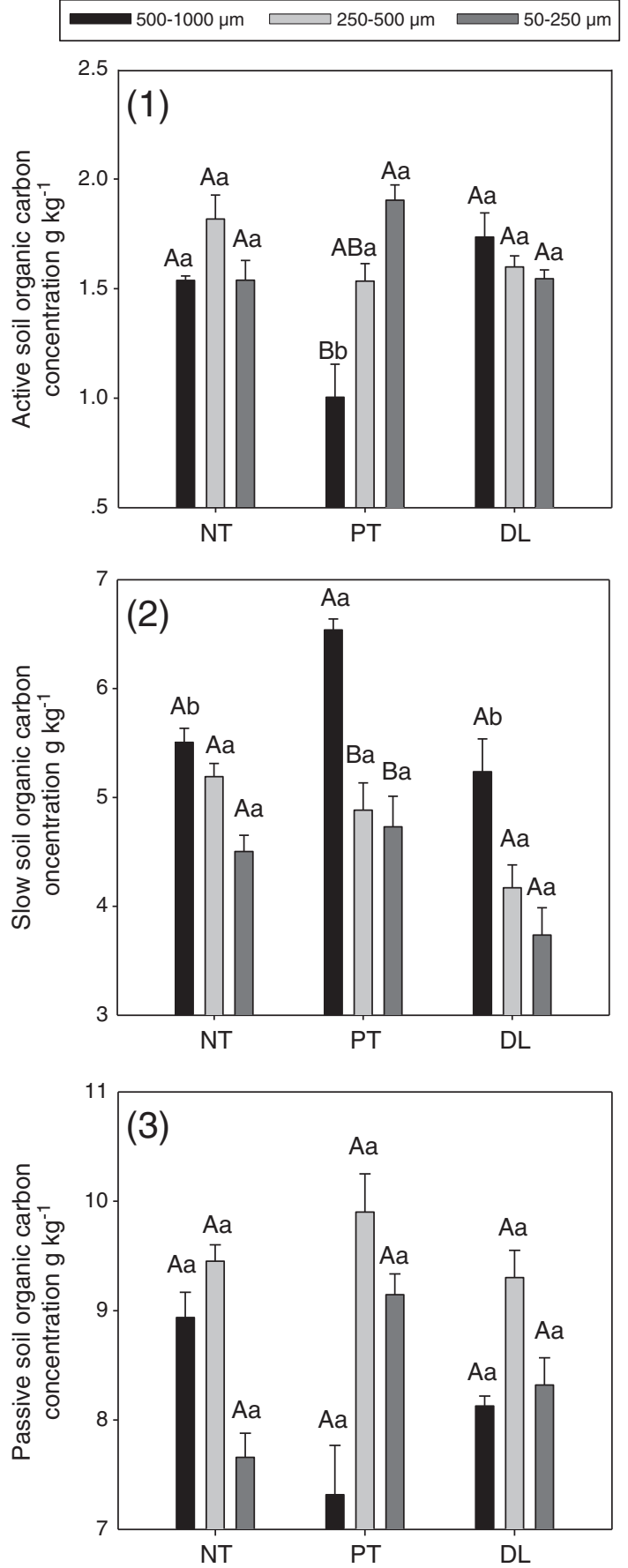

Fig. 2. Different fractions of SOC concentration in different tillage systems and wet-sieved aggregates.

(1), (2) and (3) represents active, slow and passive organic carbon content, respectively. Note: Same capital letter X indicates no significant difference of SOC concentration at $\mathrm{P}<0.05$ level in the different aggregates-size, same lowercase $\mathrm{x}$ stands for no significant difference of SOC content at $\mathrm{P}<0.05$ level in different tillage systems.

that SOC is difficult to decompose, when the value of alky-C/O-alky$\mathrm{C}$ ratio is relatively high. The aliphatic- $\mathrm{C} /$ aromatics- $\mathrm{C}$ ratio is a predictor to reveal the complexity of the chemical composition of SOC - the higher this value, the simpler chemical composition of SOC. The hydrophobic-C/hydrophilic-C ratio can forecast the hydrophobic extent of SOC - the higher this value, the more stable for the SOC.

Alkyl-C/O-alkyl-C and hydrophobic-C/hydrophilic-C ratios are consistently greater in NT, averaging $14.6 \%$ and $11.3 \%$ greater than PT, $26.3 \%$ and $9.1 \%$ larger than DL, respectively. However, aliphatic-C/aromatics-C is $6.9 \%$ and $19.2 \%$ higher in PT than in NT and DL, respectively (Table 3 ). 


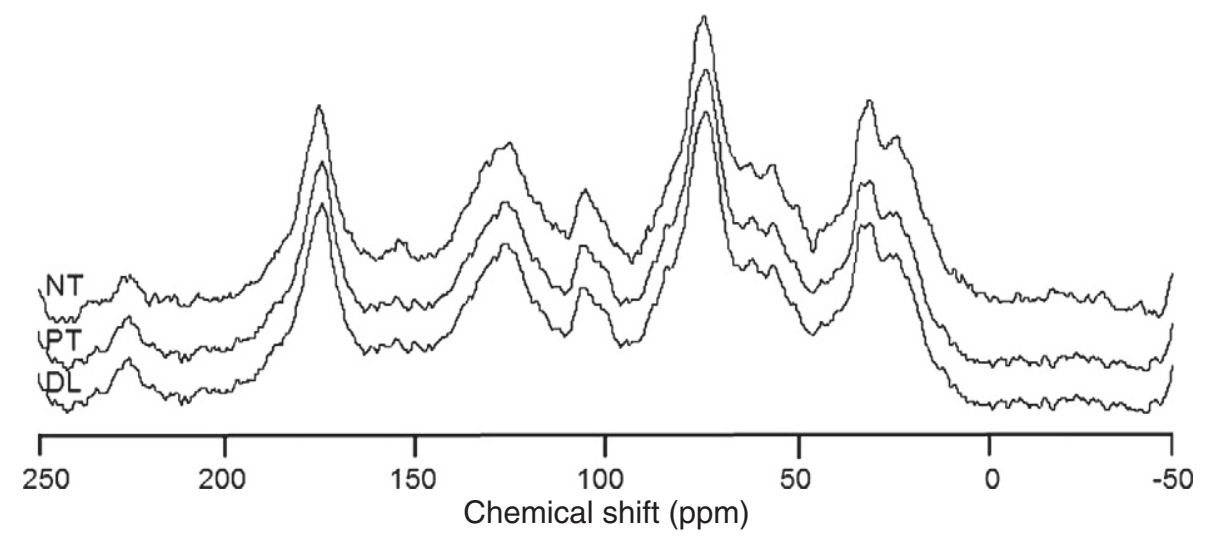

Fig. 3. The ${ }^{13} \mathrm{C}$ NMR spectrum of macro-aggregates $(>250 \mu \mathrm{m})$ in different tillage systems.

\subsubsection{Pearson relationship of the fractions and composition of SOC}

SOC is directly related to slow $C$ and passive $C$, but the negative interaction was observed between active $C$ and slow $C$ (Table 4 ) in the Pearson analysis, which means that active $\mathrm{C}$ and slow $\mathrm{C}$ remain a tradeoff relationship. There is a positive correlation between SOC and alkyl-C. Active $\mathrm{C}$ is correlated positively with O-alkyl-C, especially C2-C6 carbohydrates, negatively with aromatic-C. Similarly, slow $\mathrm{C}$ is positively associated with the carbonyl-C, especially AKQ-C (aldehyde-C, ketonic-C and quinone- $\mathrm{C}$ ). Passive $\mathrm{C}$ was significantly related to the aromatic- $\mathrm{C}$ (positive) and O-alkyl-C (negative). In addition, our results indicated that the anticorrelation existed between alkyl-C and O-alkyl-C and aromatic-C, O-alkyl-C were directly correlated to C2-C6 carbohydrates and anomatic- $\mathrm{C}(\mathrm{C} 1)$, but no relationship was found in the O-alkyl-C and methoxyl-C. The carbonyl-C was reverse to AKQ-C, but indicated little prediction of carboxylic acid-C.

\section{Discussion}

\subsection{Tillage impacts on SOC}

Tillage mainly changed the environment for micro-organisms and distribution of SOC to affect SOC concentration, thus long-term tillage resulted in a significant loss of total soil organic matter (McArthur et al., 2001). However, some reports agreed with the inverse result, that is, an increase of SOC concentration was observed in PT vs. NT systems (e.g. Christopher et al., 2009; Humberto and Lal, 2008). They explained that being mechanically disrupted by PT contributed to residue incorporation with soils. Our results indicated that SOC concentration at $0-20 \mathrm{~cm}$ depth did not show a statistical difference among the three tillage systems. It can be attributed to the following two reasons. First, our experiment site shows signs of serious wind erosion, and loss of soil and water, for while PT disturbs soils and results in the decomposition of SOC, climate is also associated with the soils of NT. Second, straw with vertical incorporation is difficult to combine into the soil as new SOC in NT system (Zhao and Lv, 2009). Consequently, NT is rather difficult to make the contribution of $\mathrm{C}$ accumulation.

The different sizes of the aggregates and tillage systems can both induced the statistical variance of SOC concentration in aggregates. Our results found an increase of SOC concentration in macro-aggregates vs. micro-aggregates; we can apply the theory of aggregate hierarchy (Oades and Waters, 1991; Tisdall and Oades, 1982) to explain our results. Aggregate theory states that micro-aggregates are bound together into macro-aggregates by organic binding agents. There is considerable evidence in published studies (e.g. Pikul et al., 2009; Puget et al., 2000; Six et al., 2000). The difference of SOC concentration in three tillage systems may be primarily due to the following reasons. First, the majority increase of SOC in NT occurred in macro-aggregates. Moreover, tillage aggravates the mineralization of SOC in macro-aggregates, with breaking macro-aggregate into micro-aggregates (Zibilske and Bradford, 2007), finally, increased SOC concentration of relatively Cdepleted micro-aggregates in soils. Second, many reports concluded that SOC concentration of different aggregates was higher for NT and RT (ridge tillage, similar to DT) compared with PT in the depth of 0-5 cm, nevertheless, the inverse effects was found in the depth of 5-20 cm or $10-15 \mathrm{~cm}$ (Six et al., 1999; Zibilske and Bradford, 2007). Similar researches deduced that more SOC concentration from the maize conveyed into the stable SOC in tilled soil than untilled soil, and favoring formation in the micro-aggregates (Stemmer et al., 1999).

The treatment in which tillage was incorporated in the soils, was found to lose active SOC and increase slow SOC in the aggregates of $500-1000 \mu \mathrm{m}$. However, different fractions of SOC in $50-500 \mu \mathrm{m}$

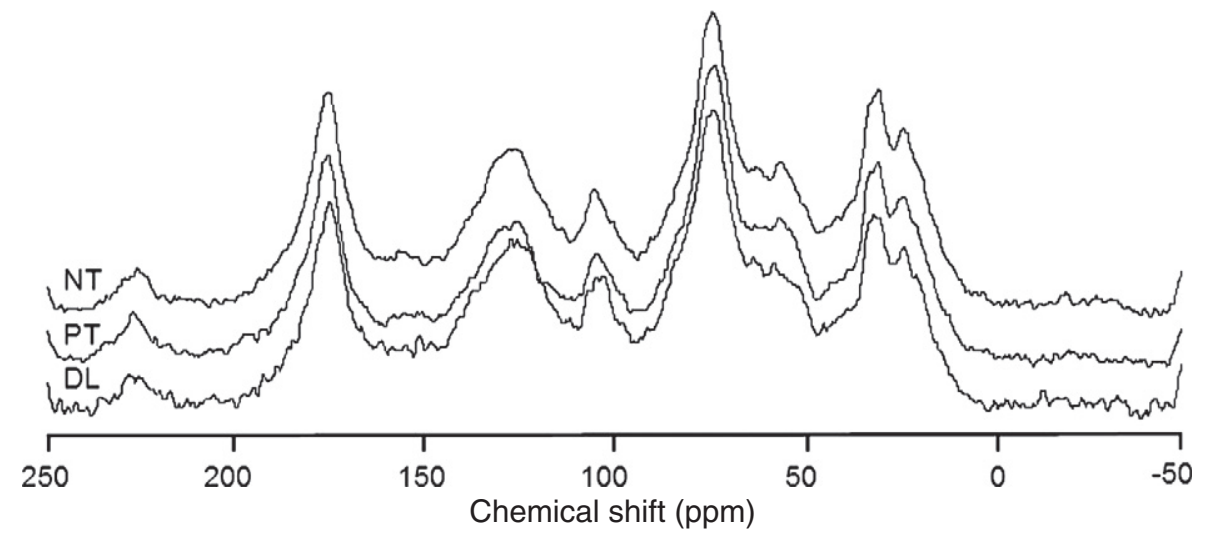

Fig. 4. The ${ }^{13} \mathrm{C}$ NMR spectrum of micro-aggregates $(<250 \mu \mathrm{m})$ in different tillage systems. 
Table 1

Compositions of the chemical functional groups for the wet-sieved macro-aggregates ( $>250 \mu \mathrm{m})$ under different tillage systems (\%).

\begin{tabular}{|c|c|c|c|c|c|c|c|c|c|c|c|}
\hline \multirow[t]{2}{*}{ Till } & \multirow[t]{2}{*}{ Alkyl } & \multirow{2}{*}{$\begin{array}{l}\text { O- } \\
\text { alkyl }\end{array}$} & \multicolumn{3}{|l|}{ O-alkyl-C } & \multirow[t]{2}{*}{ Aromatic } & \multicolumn{2}{|c|}{ Aromatic-C } & \multirow[t]{2}{*}{ Carbonyl } & \multicolumn{2}{|l|}{ Carbonyl-C } \\
\hline & & & Methoxyl & C2-C6 & $C(C 1)$ & & Aryl & Phenolic & & Carbonxylic & AKQ \\
\hline NT & 22.37 & 39.52 & 6.08 & 25.32 & 6.48 & 22.22 & 16.73 & 6.65 & 15.85 & 6.58 & 6.06 \\
\hline PT & 19.30 & 41.19 & 6.16 & 26.38 & 6.80 & 22.65 & 16.69 & 5.95 & 16.86 & 6.74 & 6.82 \\
\hline DL & 18.97 & 43.64 & 6.24 & 28.21 & 7.36 & 22.52 & 16.76 & 5.86 & 14.87 & 6.65 & 6.78 \\
\hline
\end{tabular}

Note: AKQ shows aldehyde-C, ketonic-C and quinone-C.

aggregates were associated with no differences among the three tillage systems. This was because macro-aggregates were bound by labile roots and hyphae, they were easily broken down by disturbance, but the binding agents of micro-aggregates derived from the persistent organic carbon. As a consequent, macroaggregates are easily affected by tillage (Tisdall and Oades, 1982), and a higher active SOC concentration was observed in NT and DL compare with PT. Reasons for the variation could also directly include the faster decomposition of light SOC under tillage disturbance (Dalal and Chan, 2001). Different SOC fractions transformed each other, part of active $\mathrm{SOC}$ emissions of $\mathrm{CO}_{2}$, and part of it transformed into the steady-state SOC. A similar study of Murage and Voroney (2008) reported that PT was favoring to decompose crop residues into structural organic carbon (slow SOC). Therefore, it was the reason why slow SOC in PT is greater than NT and DL.

\subsection{Tillage impacts on the composition of SOC}

${ }^{13} \mathrm{C}$ NMR spectrum indicated that although the resonance peak of SOC was very similar under various tillage systems, the content of SOC structure had great differences. The chemical shift region of alkyl-C appears at 23 and $30 \mathrm{ppm}$, that result from acetate fraction of hemicellulose and polymethylene of fatty acid, wax, and resin (Chen and Chiu, 2003; Tinoco et al., 2004), respectively. 55 ppm is ascribed to the indicative resonance band in syringyl and guaiacyl units of lignin; $62 \mathrm{ppm}$ can be assignable to carbinol alcohol-C structure. Chemical shift between $\delta=50$ and $60 \mathrm{ppm}$ can be attributable to the methoxyl-C. The signal around $73 \mathrm{ppm}$, between $\delta=60$ and 95 ppm represents C2 to C6 structures such as cellulose, hemicellulose, and other polymeric carbohydrates (Solomon et al., 2007; Zhang et al., 2009). And the peak of $103 \mathrm{ppm}$ is due to nonprotonated resonance peaks from tannin and lignin; 124 and $150 \mathrm{ppm}$ originate from C-, $\mathrm{H}$-substituted aromatic-C and $\mathrm{O}$ substituted aromatic- $\mathrm{C}$, respectively. Generally, the phenolic- $\mathrm{C}$ of $150 \mathrm{ppm}$ occurs in the process of lignin decomposing (Bartuska et al., 1980), however, the $150 \mathrm{ppm}$ resonance peak is very weak in this experiment and this may indicate that the resonance peak of $150 \mathrm{ppm}$ mainly comes from some decomposition material of straw or stubble but not lignin, or some phenolic-C coming from decomposing materials of lignin. The chemical shift around $173 \mathrm{ppm}$ attributes to carboxyl-C of the amide and polypeptide. The shape of alkyl-C, O-alkyl-C, and aromatic-C region in macroaggregates is wider for NT than for PT and DL, and the shape of the alkyl-C, aromatic- $\mathrm{C}$, and carbonyl- $\mathrm{C}$ regions in micro-aggregates is also broader for NT than for PT and DL. These indicate that a more steady-state chemical composition of SOC is observed in NT compared with PT and DL (Skjemstad and Dalal, 1987).

NT has the highest alkyl-C concentration among the three tillage systems. The accumulation of alkyl-C was mainly attributable to polymethylene, which comes from the stubble's aerobic decomposition (Lorenz et al., 2010), and NT was the only tillage system that did not disturb the soils in our study. This is consistent with the finding of Schnitzer et al. (2006) and Ding et al. (2002). The highest O-alkyl-C concentration was found in DL, because of its relatively large amount of straw returning, great quantities of roots (Qin et al., 2006), and high microorganism activity (Wu et al., 2008). The methoxyl-C content was similar in different tillage systems. Because of the recalcitrant chemical structure of methoxyl-C, methoxyl-C is relatively enriched in the topsoil when other O-alkyl-C is prone to oxidation. The methoxyl-C only comes from lignin (Oades et al., 1987), but the lignin content of maize straw is very low, lignin has little chance to impact the chemical composition of SOC. Consequently, it can be deduced that the increase of O-alkyl-C under DL was mainly from C2-C6 carbohydrate and anomeric-C. The aromatic- $\mathrm{C}$ concentration of macro-aggregates has a similar value in the different tillage systems, while PT shows the lowest value of aromatic-C concentration in micro-aggregates. It does not correspond with Mahieu et al. (1999), Ding et al. (2002), and Pérez et al. (2004). Moreover, the degeneration of micro-organism and straw burning also increased the aromaticity of SOC structure (Ponomarenko and Anderson, 2001), which requires further research. The relatively greater carbonyl-C content was observed under PT, according to the explanation of Mahieu et al. (2002) that original SOC appears to be diluted, with increase of crop residues, and results in an SOC with lower concentration of carbonyl-C. The conclusion of Kiem et al. (2000) also proved our results.

Decomposability and complexity of SOC can be responded by the ratios of different functional groups of SOC. Our study results demonstrated that the SOC would turn into a more complicated structure, when it was associated with NT, SOC would converse a simpler structure, when it was associated with PT, and chemical composition of SOC under DL was between NT and PT. Therefore, it can be concluded that NT system can protect SOC and form a more stable structure of SOC.

\subsection{Relationship between SOC fractions and chemical composition}

Mean residence time (MRT) of active, slow, and passive SOC is about $1-5,20-40$, and 200-1500 years, respectively (Parton et al., 1987), so the chemical structure tends to stabilize from active to passive SOC. Kiem et al. (2000) compared the chemical structure of

Table 2

Compositions of the chemical functional groups for the wet-sieved micro-aggregates $(<250 \mu \mathrm{m})$ under different tillage systems $(\%)$.

\begin{tabular}{|c|c|c|c|c|c|c|c|c|c|c|c|}
\hline \multirow[t]{2}{*}{ Till } & \multirow[t]{2}{*}{ Alkyl } & \multirow{2}{*}{$\begin{array}{l}\text { O- } \\
\text { alkyl }\end{array}$} & \multicolumn{3}{|l|}{ O-alkyl-C } & \multirow[t]{2}{*}{ Aromatic } & \multicolumn{2}{|c|}{ Aromatic-C } & \multirow[t]{2}{*}{ Carbonyl } & \multicolumn{2}{|l|}{ Carbonyl-C } \\
\hline & & & Methoxyl & $\mathrm{C} 2-\mathrm{C} 6$ & $\mathrm{C}(\mathrm{C} 1)$ & & Aryl & Phenolic & & Carbonxylic & AKQ \\
\hline NT & 21.95 & 40.16 & 6.57 & 25.53 & 6.27 & 21.65 & 16.54 & 5.05 & 16.24 & 6.06 & 2.55 \\
\hline PT & 21.26 & 42.18 & 6.87 & 26.28 & 6.29 & 19.92 & 15.2 & 5.69 & 16.66 & 6.82 & 3.38 \\
\hline DL & 18.95 & 42.51 & 6.73 & 27.12 & 6.69 & 23.69 & 17.9 & 5.87 & 14.85 & 6.78 & 1.89 \\
\hline
\end{tabular}

Note: AKQ shows aldehyde-C, ketonic-C and quinone-C 
Table 3

The ratios of different functional groups for the soil under different tillage systems.

\begin{tabular}{|c|c|c|c|c|c|c|}
\hline \multirow{2}{*}{$\frac{\text { Tillage systems }}{\text { Aggregates }}$} & \multicolumn{2}{|l|}{ NT } & \multicolumn{2}{|l|}{ PT } & \multicolumn{2}{|l|}{ DL } \\
\hline & Mac & Mic & Mac & Mic & Mac & Mic \\
\hline Alkyl-C/O-alkyl-C & 0.56 & 0.55 & 0.47 & 0.50 & 0.43 & 0.45 \\
\hline Aliphatic-C/aromatics-C* & 2.79 & 2.87 & 2.67 & 3.19 & 2.78 & 2.59 \\
\hline Hydrophobic-C/hydrophilic-C & 0.81 & 0.77 & 0.72 & 0.70 & 0.71 & 0.74 \\
\hline
\end{tabular}

Note: $\quad$ Aliphatic $/$ Aromatics $=($ Alkyl-C + O-alkyl-C $) /$ Aromatics-C; Hydrophobic-C $/$ Hydrophilic- $\mathrm{C}=($ Alkyl-C + Aromatic- $\mathrm{C}) /(\mathrm{O}$-alkyl-C + Carbonyl $\mathrm{C})$.

Mac and mic represent macro-aggregates $(>250 \mu \mathrm{m})$ and micro-aggregates $(<250 \mu \mathrm{m})$, respectively.

fertilized soils with C-depleted soils to prove that various carbon compositions differed, with respect to the extent of this carbon decrease in C-depleted soils, and the decrease was shown to follow the order of O-alkyl-C $>$ alkyl-C $>$ carboxyl-C $>$ aromatic-C. The study of Dieckow et al. (2009) also concluded that aromatic-C structure was recalcitrant, and O-alkyl-C structure was labile. Our results indicated that active, slow, and passive SOC had a positive correlation with O-alkyl-C (particular C2-C6 carbohydrates), carbonyl-C (particular aldehyde- $\mathrm{C}$, ketonic- $\mathrm{C}$ and quinone- $\mathrm{C}$ ), and aromatic- $\mathrm{C}$, respectively. Consequently, we could deduce that active SOC was composed by more O-alkyl-C, slow SOC was composed by more carbonyl-C, and passive SOC was composed by more aromatic-C. The O-alkyl-C and alkyl-C had a trade-off relationship in Table 4, and the similar results were obtained by Kiem et al. (2000).

\section{Conclusions}

Long-term tillage systems significantly affect the fractions and chemical composition of SOC. Macro-aggregates resulted in a greater SOC concentration compared with micro-aggregates, but PT led to more SOC concentration in 50-250 $\mu \mathrm{m}$ at the depth of $0-20 \mathrm{~cm}$. Furthermore, NT as well as DL associated with a higher active SOC and lower slow SOC then PT, in the macro-aggregates. NT mainly improved the alkyl-C, PT was favorable to increase carbonyl-C, and DL was associated with the O-alkyl-C, particularly C2-C6 carbohydrate and anomeric C (C1) polysaccharides. With an increase of the alkyl$\mathrm{C} / \mathrm{O}-$ alkyl-C ratios and hydrophobic-C/hydrophilic-C ratios of NT, as well as the increase of aliphatic-C/aromatics- $\mathrm{C}$ ratios in PT, we could deduce that NT made a more complicated SOC structure, but PT simplified the SOC composition. Consequently, NT is an effective strategy to protect the SOC composition. Furthermore, we concluded that active $\mathrm{C}$ was mainly composed of $\mathrm{C} 2-\mathrm{C} 6$ carbohydrates and anomericC (C1) of O-alkyl-C, slow C consisted of the aldehyde-C, ketonic-C, and quinone- $\mathrm{C}$ of carbonyl- $\mathrm{C}$, and passive $\mathrm{C}$ dominated in the aromatic-C.

\section{Acknowledgments}

This study was financed by the country's "12th Five-Year Plan" project (201103001). We are grateful to Gary M. Sanders from the Graduate University of the Chinese Academy of Sciences, and Binfeng Sun from the Research Center for Eco-Environmental Sciences, Chinese Academy of Sciences, for editing our paper.

\section{References}

Bao, S.D., 2000. Soil Agricultural Chemistry Analysis. China Agriculture Press, Beijing, pp. 30-34 (In Chinese).

Bartuska, V.J., Maciel, G.E., Bolker, H.I., Fleming, B., 1980. Structural studies of lignin isolation procedures by ${ }^{13} \mathrm{C}$ NMR. Holzforschung 34, 214-217.

Chen, J.S., Chiu, C.Y., 2003. Characterization of soil organic matter in different particlesize fractions in humid subalpine soils by $\mathrm{CP} / \mathrm{MAS}{ }^{13} \mathrm{C}$ NMR. Geoderma 117 129-141.

Christopher, S.F., Lal, R., Mishra, U., 2009. Regional study of no-till effects on carbon sequestration in Midwestern United States. Soil Science Society of America Journal 73, 207-216.

Dalal, R.C., Chan, K.Y., 2001. Soil organic matter in rain-fed cropping systems of the Australian Cereal Belt. Australian Journal of Soil Research 39, 435-464.

Dieckow, J., Baye, C., Conceicxao, P.C., Zanatta, J.A., Martin-Neto, L., Milori, D.B.M., Salton, J.C., Macedo, M.M., Mielniczuk, J., Hernani, L.C., 2009. Land use, tillage, texture and organic matter stock and composition in tropical and subtropical Brazilian soils. European Journal of Soil Science 60, 240-249.

Ding, G., Novak, J.M., Amarasiriwardena, D., Hunt, P.G., Xing, B., 2002. Soil organic matter characteristics as affected by tillage management. Soil Science Society of America Journal 66, 421-429.

Franzluebbers, A.J., Arshad, M.A., 1997. Particulate organic carbon content and potential mineralization as affected by tillage and texture. Soil Science Society of America Journal 61, 1382-1386.

Goncalves, N.C., Dalmolin, S.D.R., Dick, P.D., Knicker, H., Klamt, E., Kögel-Knabner, I., 2003. The effect of $10 \% \mathrm{HF}$ treatment on the resolution of CP MAS ${ }^{13} \mathrm{C}$ NMR spectra and on the quality of organic matter in Ferralsols. Geoderma 116, 373-392.

Helfrich, M., Ludwig, B., Buurman, P., Flessa, H., 2006. Effect of land use on the composition of soil organic matter in density and aggregate fractions as revealed by solidstate ${ }^{13} \mathrm{C}$ NMR spectroscopy. Geoderma 136, 331-341.

Humberto, B., Lal, R., 2008. No-Tillage and soil profile carbon sequestration: an on-farm assessment. Soil Science Society of America Journal 72, 693-701.

Kemper, W.D., 1986. Aggregate stability and size distribution, Methods of Soil Analysis. Part I. Physical and Mineralogical Methods, 2nd ed. : In: Klute, A. (Ed.), Agro. Monogr., 9. ASA and SSSA, Madison, WI, pp. 383-411. 425-442.

Kiem, R., Knicker, H., Körschens, M., Kögel-Knabner, I., 2000. Refractory organic carbon in C-depleted arable soils, as studied by ${ }^{13} \mathrm{C}$ NMR spectroscopy and carbohydrate analysis. Organic Geochemistry 31, 655-668.

Leavitt, S.W., Follett, R.F., Paul, E.A., 1996. Estimation of the slow and fast cycling soil organic carbon pools from $6 \mathrm{~N} \mathrm{HCl}$ hydrolysis. Radiocarbon 38, 231-239.

Lorenz, K., Lal, R., Jiménez, J.J., 2010. Characterization of soil organic matter and black carbon in dry tropical forests of Costa Rica. Geoderma 158, 315-321.

Mahieu, N., Powlson, D.S., Randall, E.W., 1999. Statistical analysis of published carbon13 CPMAS NMR spectra of soil organic matter. Soil Science Society of America Journal 63, 307-319.

Table 4

Correlation coefficient of the fraction and composition of SOC.

\begin{tabular}{|c|c|c|c|c|c|c|c|c|}
\hline & $\mathrm{SOC}$ & Active C & Slow C & Passive C & alkyl-C & O-alkyl-C & Aromatic-C & Carbonyl-C \\
\hline Active C & -0.36 & & & & & & & \\
\hline Slow C & $0.54^{*}$ & $-0.49^{*}$ & & & & & & \\
\hline Passive C & $0.49^{*}$ & -0.39 & 0.18 & & & & & \\
\hline Alkyl-C & $0.69^{*}$ & 0.36 & 0.22 & 0.35 & & & & \\
\hline O-alkyl-C & -0.33 & $0.52^{*}$ & -0.36 & $-0.47^{*}$ & $-0.79^{* *}$ & & & \\
\hline Aromatic-C & 0.07 & $-0.63^{*}$ & 0.01 & $0.49^{*}$ & $-0.59^{*}$ & 0.12 & & \\
\hline Carbonyl-C & 0.14 & 0.35 & $0.50^{*}$ & -0.08 & 0.44 & $-0.51^{*}$ & $-0.61^{*}$ & \\
\hline Methoxyl-C & -0.15 & 0.38 & -0.42 & -0.03 & 0.25 & 0.12 & $-0.58^{*}$ & 0.23 \\
\hline $\mathrm{C} 2-\mathrm{C} 6$ & -0.22 & $0.63^{*}$ & -0.34 & $-0.54^{*}$ & $-0.73^{* *}$ & $0.98^{* *}$ & 0.03 & -0.45 \\
\hline C1 & 0.19 & 0.40 & 0.12 & 0.02 & $-0.57^{*}$ & $0.49^{*}$ & 0.40 & -0.41 \\
\hline Aryl-C & 0.06 & $-0.61^{*}$ & -0.05 & $0.52^{*}$ & $-0.48^{*}$ & 0.07 & $0.96^{* *}$ & $-0.67^{*}$ \\
\hline Phenolic-C & 0.16 & $-0.56^{*}$ & 0.01 & $0.47^{*}$ & $-0.63^{*}$ & 0.18 & $0.88^{* *}$ & -0.47 \\
\hline Carboxylic-C & -0.01 & 0.14 & -0.25 & -0.29 & $0.53^{*}$ & 0.33 & 0.08 & -0.10 \\
\hline AKQ-C & 0.24 & 0.32 & $0.55^{*}$ & -0.10 & 0.31 & $-0.49^{*}$ & $-0.51^{*}$ & $0.88^{\text {** }}$ \\
\hline
\end{tabular}

AKQ shows aldehyde-C, ketonic- $C$ and quinone-C.

* Stands for Pearson correlation coefficient significant in $\mathrm{P}<0.05$ level.

** Represents Pearson correlation coefficient significant in $\mathrm{P}<0.01$ level. 
Mahieu, N., Olk, D.C., Randall, E.W., 2002. Multinuclear magnetic resonance analysis of two humic acid fractions from lowland rice soils. Journal of Environmental Quality 31, 421-430.

McArthur, D.F.E., Huang, P.M., Kozak, L.M., 2001. Impact of long-term cultivation on the status of organic matter and cadmium in soil. Canadian Journal of Soil Science 81, 349-355.

Meng, Kai, Liu, Yuejie, 2008. Analysis on the retrogressive stages and intensity of terra near. System Sciences and Comprehensive Studies in Agriculture 24, 773-776 (In Chinese with English abstract).

Murage, E.W., Voroney, R.P., 2008. Distribution of organic carbon in the stable humic fractions as affected by tillage management. Canadian Journal of Soil Science 88, 99-106.

Oades, J.M., Waters, A.G., 1991. Aggregate hierarchy in soils. Australian Journal of Soil Research 29, 815-828.

Oades, J.M., Vassallo, A.M., Waters, A.G., Wilson, M.A., 1987. Characterization of organic matter in particle size and density fractions from a red-brown earth by solid-state ${ }^{13}$ C N.M.R. Australian Journal of Soil Research 25, 71-82.

Parton, W.J., Schimel, D.S., Cole, C.V., Ojima, D.S., 1987. Analysis of factors controlling soil organic matter levels in great plains grasslands. Soil Science Society of America Journal 51, 1173-1179.

Pérez, M.G., Martin-Neto, L., Saab, S.C., Novotny, H.E., Miloria, M.B.P., Bagnatod, S.V., Colnagoa, L.A., Meloe, W.J., Knicker, H., 2004. Characterization of humic acids from a Brazilian Oxisol under different tillage systems by EPR, 13C NMR, FTIR and fluorescence spectroscopy. Geoderma 118, 181-190.

Pikul, J.L., Chilom, G., Rice, J., Eynard, A., Schumacher, T.E., Nichols, K., Johnson, J.M.F., Wright, S., Caesar, T., Ellsbury, M., 2009. Organic matter and water stability of field aggregates affected by tillage in South Dakota. Soil Science Society of America Journal 73, 197-206.

Ponomarenko, E.V., Anderson, D.W., 2001. Importance of charred organic matter in black Chernozem soils of Saskatchewan. Canadian Journal of Soil Science 81, 285-297.

Preston, C.M., Newman, R.H., Rother, P., 1994. Using ${ }^{13} \mathrm{C}$ CPMAS NMR to assess effects of cultivation on the organic carbon of particle size fractions in a grassland soil. Soil Science 157, 26-35.

Puget, P., Chenu, C., Balesdent, J., 2000. Dynamics of soil organic matter associated with particle-size fractions of water-stable aggregates. European Journal of Soil Science 51, 595-605.

Qin, R.J., Stamp, P., Richner, W., 2006. Impact of tillage on maize rooting in a Cambisol and Luvisol in Switzerland. Soil and Tillage Research 85, 50-61.

Qiu, J.J., Wang, L.G., Tang, H.J., Li, H., Li, C.S., 2004. Study on the situation of soil organic carbon storage in arable lands in northeast China. Scientia Agicultura Sinica 37. 1166-1171 (In Chinese with English abstract).

Schnitzer, M., McArthur, D.F.E., Schulten, H.R., Kozak, L.M., Huang, P.M., 2006. Longterm cultivation effects on the quantity and quality of organic matter in selected Canadian prairie soils. Geoderma 130, 141-156.
Six, J., Elliott, E.T., Paustian, K., 1999. Aggregate and soil organic matter dynamics under conventional and no-tillage systems. Soil Science Society of America Journal 63, 1350-1358.

Six, J., Paustian, K., Elliott, E.T., Combrink, C., 2000. Soil structure and organic matter: I. Distribution of aggregate-size classes and aggregate-associated carbon. Soil Science Society of America Journal 64, 681-689.

Skjemstad, J.O., Dalal, R.C., 1987. Spectroscopic and chemical differences in organic carbon of two Vertisols subjected to long periods of cultivation. Australian Journal of Soil Research 25, 323-335.

Solomon, D., Lehmann, J., Kinyangi, J., Amelyng, W., Pell, A., Riha, S., Ngoze, S., Verchot, L., Mbugua, D., Jemstad, J., Shafer, T., 2007. Long-term impacts of anthropogenic perturbations on dynamics and speciation of organic carbon in tropical forest and subtropical grassland ecosystems. Global Change Biology 13, 511-530.

Sotomayor-Ramírez, D., Espinoza, Y., Rámos-Santana, R., 2006. Short-term tillage practices on soil organic matter pools in a tropical Ultisol. Aust. J. Soil Res. 44,687-693.

Stemmer, M., Lützow, M., Kandeler, E., Pichlmayer, F., Gerzabek, M.H., 1999. The effect of maize straw placement on mineralization of $\mathrm{C}$ and $\mathrm{N}$ in soil particle size fractions. European Journal of Soil Science 50, 73-86.

Tan, Z., Lal, R., Owens, L., Izaurralde, R.C., 2007. Distribution of light and heavy fractions of soil organic carbon as related to land use and tillage practice. Soil and Tillage Research 92, 53-59.

Tinoco, P., Almendros, G., Gonzaa, F.J., Lankes, U., Dietrich, H., Demann, L., 2004. Analysis of carbon and nitrogen forms in soil fractions after the addition of ${ }^{15} \mathrm{~N}$-compost by ${ }^{13} \mathrm{C}$ and ${ }^{15} \mathrm{~N}$ nuclear magnetic resonance. Journal of Agricultural and Food Chemistry 52, 5412-5417.

Tisdall, J.M., Oades, J.M., 1982. Organic matter and water-stable aggregates in soils. Journal of Soil Science 33, 141-163.

Wu, H.Y., Fan, Z.W., Liu, C.G., Wang, H.L., Zhou, P., Liu, W.R., 2008. Analysis on the regularity and influence factors of change of soil micro flora under maize planting technology of conservation tillage. Journal of Maize Sciences 16, 135-139.

Yang, X.M., Kay, B.D., 2001. Impacts of tillage practices on total, loose- and occludedparticulate, and humified organic carbon fractions in soils within a field in southern Ontario. Canadian Journal of Soil Science 81, 149-156.

Yu, R., Xu, M.G., Wang, B.R., 2005. Study on methods for determining labile orange matter of soils. Soil Fertility 2, 49-52 (In Chinese with English abstract).

Zhang JJ. Dou, S, Zhu, P. Gao, HJ. Song X.Y, Wang, L.C, 2009. Effect of long-term application of organic fertilizer on structural characteristics of humin in black soil-a solid-state ${ }^{13} \mathrm{C}$ NMR study. Scientia Agricultura Sinica 42, 2223-2228 (In Chinese with English abstract).

Zhao, H., Lv, Y.Z., 2009. The effect of conservation tillage on the structural characteristics of Fluvo-aquic soil. Ecology and Environmental Sciences 18, 1956-1960 (In Chinese with English abstract).

Zibilske, L.M., Bradford, J.M., 2007. Soil aggregation, aggregate carbon and nitrogen, and moisture retention induced by conservation tillage. Soil Science Society of America Journal 71, 793-802. 